\title{
Industrial Change and Platform Enterprises Innovation Model
}

\author{
Jinjiang $\mathrm{He}^{1, \mathrm{a}}$,Qi Zhang ${ }^{1,2, \mathrm{~b}^{*}}$ and Ning Cai ${ }^{1, \mathrm{c}}$ \\ ${ }^{1}$ School of Public Administration, Zhejiang University, Hangzhou 310058, China \\ ${ }^{2}$ Lishui University, Lishui, 323000, China

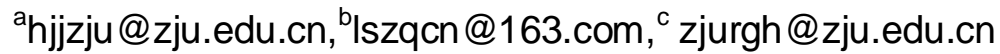 \\ *The corresponding author
}

Keyword: Platform; Enterprises innovation model; Platform enterprises

\begin{abstract}
This research will follow "the typical platform of enterprise innovation model innovation model and industry and its organizational mechanism - the future innovation model and industry and its organization - the future of small and medium platform enterprise development proposal" logical framework to study the typical platform enterprise innovation model, Future platform enterprises may be innovative areas and business models for China's small and medium-sized Internet companies to build and business model innovation to provide decision-making recommendations.
\end{abstract}

\section{Introduction}

A new round of technological revolution and industrial transformation has spawned a large number of new technologies, new industries, new formats, new models. In this context the birth of the platform enterprise development momentum, resource integration capabilities continue to increase, such as Alibaba, Tencent and other Internet companies gathered a lot of resources at the same time, with the help of innovative business model and subversion and reconstruction of traditional business logic, cross-border development of these Internet giants the only strategic choice, which the traditional industries and their industrial development has had a revolutionary impact. It can be said that the Internet platform business is to promote China's economic restructuring and commercial logic reconstruction of the important support. At present, the Internet enterprises with platform characteristics continue to emerge, but most of them are constantly dying, the average life cycle of enterprises is only 1.5 years. For small and medium-sized Internet enterprises, the existing typical platform for enterprise innovation model for its development has important reference. We need to analyze the innovation model of the typical platform, clarify the factors that affect the innovation model, explore the mechanism of the innovation mode of the platform for the industry and its industrial organization. Thus, the study of this paper has important practical value.

\section{Literature Review}

Platform Enterprise. The concept of "platform" first appeared in research literature on new product development. Robertson and Ulrich (1998) argue that a product platform is a collection of products that are generated by sharing. At present, the concept of the platform is widely used by management scholars in products, technology systems and transactions. A platform is essentially a trading space or place that can exist in the real world or in a virtual network space that directs or facilitates transactions between both parties or parties and strives to attract transactions by charging the appropriate fees. When a platform satisfies these two conditions, it can choose two design methods: the use of existing capabilities or architecture; the establishment of new capabilities and architecture, which means that the three levels are the qualifying conditions for the platform, for the end of the platform, whether it is possible to emerge, depending on the three levels of industrial technology, activity systems and value systems. When a platform is formed, openness, modularity, and quality control will be an important factor influencing the success of it. Chinese scholars have also made a related research on the formation of the platform, such as This paper intends to 
combine the external factors (national level, industry level, entrepreneur level) and internal factors (existing business area selection, innovation model) to influence the factors of the platform enterprise Do in-depth discussion.

Platform Innovation Model. At present, the platform enterprise innovation model can be mainly from three perspectives. First, the organizational perspective, from the organizational perspective on the platform business model innovation analysis more attention to the Internet and when the intervention platform for the existence of bilateral innovation, platform enterprise pricing model, charging model innovation methods and path, combined with value network, the ecosystem and other related theories, through the construction of the corresponding mathematical economic model, analysis of platform business model innovation. Third, the specific platform analysis, different platform enterprises have different innovative models, mainly in the mobile service platform industry and content-based platform area. Based on the above three perspectives, this paper systematically combs the innovation mode of the existing platform enterprises from the two aspects of business innovation and business model innovation, which provides the basis for the future development of the platform enterprises.

Relationship. With the "Internet $+"$ concept put forward, the Internet information technology has been rapid development, and penetrate into all aspects of traditional industries, the traditional industrial productivity has thus been a huge development. On one hand, the strong penetration capacity and integration capability of Internet information technology have led to the continuous expansion of the production factors of traditional industries, the continuous improvement of the quality of production factors and the continuous optimization of the distribution of production factors. On the other hand, the rapid development and expansion of the Internet has also promoted the innovation and upgrading of the traditional industrial development model and the optimization and upgrading of the traditional industrial structure. Therefore, traditional industrial organizations can obtain a large number of innovative products and production models through the Internet and other channels, providing technical support for traditional industrial production innovation. On this basis, traditional industries can continue to simulate new production models, management models and marketing models through intelligent devices to help traditional industries achieve industrial innovation.

\section{The Analysis}

Case. Combined with the understanding of industrial practice, this paper selects different types of platform enterprises to conduct research. After the comparison between enterprises and the initial screening, a total of six companies selected as a research case (as shown in Table 1). According to the type of platform enterprise development, the case enterprise will be divided into traditional enterprise platform enterprises, trading platform enterprises, entertainment platform enterprises. The innovation model in this paper refers to the innovation of the platform enterprise in the business field and the business model. Therefore, in the concrete analysis, it is discussed from these two aspects. This paper summarizes the different business models based on the development path of the case enterprise, compares the innovation of the business model in different fields.

Table 1 Case Introduction

\begin{tabular}{lll}
\hline Name & area & field \\
\hline Zhejiang Newspaper & hangzhou & Newspaper media \\
\hline Netsheng & hangzhou & Trading platform \\
Alibaba & hangzhou & Trading platform \\
Jingdong & beijing & Trading platform \\
\hline Tecent & shenzhen & Entertainment platform \\
LEtv & beijing & Entertainment platform \\
\hline
\end{tabular}

Factors. Based on the life cycle of the platform enterprises, this part divides the enterprises from the time series to the four stages of the initial period, the growth period, the outbreak period and the 
mature stage. Through the business development mode and business model of each stage, Explore the elements that affect the platform innovation model. First, we discuss innovation (includes Cloud computing, Internet of Things technology, intelligent technology) on the platform of enterprise innovation model. Second, from the business level, to further distinguish the platform of the enterprise pricing model, charging mode, resource operation and organization and other existing business model, analysis of enterprises to take the business model of the motivation.

Platform Innovation Model. In the context of innovation drive, the emergence of a new type of organizational form of the platform enterprise has a huge impact on the original industry and its industrial organization, and has been challenged by the original business logic. First, through the existing platform to sort out the field of business enterprises to explore the inherent motivation of cross-border entrepreneurship and follow the inherent logic to explore the future of the platform business enterprises may provide innovative business areas of analysis. Second, the mechanism of enterprise business model on industry and its industrial organization is mainly from three aspects: platform enterprises to change the traditional way of trading, change the traditional mode of production, so that supply and demand The two sides directly docking, emphasis on information and knowledge as the core resources and the Internet to create a rapid growth of small businesses space.

Influence on Industry. Based on the existing fields and business models of the platform enterprises, the author analyzes the future development of the platform enterprises and the impact on the industry and its industrial organizations according to the internal mechanism of innovation and business model innovation. First, through the platform of business innovation in the field of business mechanism analysis, to explore the future platform companies may be involved in the field. Second, the impact of future business model innovation on industry and its organization. Around the platform business may be involved in the future business areas.

Policy Recommendations. Based on the above research results, aiming at the innovation of business innovation and business model in the platform enterprises, taking full account of the development of the macro environment and the latest information technology both at home and abroad, it will provide suggestions for the future development of the Internet enterprises, create a model for the construction of small and medium-sized Internet enterprises and the innovation of business model. On the other hand, the subject will provide policy suggestions for the development of platform enterprises in China from the perspective of government, based on the future field, operation mechanism and innovation mode of platform enterprises.

\section{Acknowledgements}

This research was supported by Zhejiang Provincial Natural Science Foundation of China: Study on the generating mechanism of corporate strategic entrepreneurship: viewing from a perspective of network reconfiguration. NO. Y17G020006.

\section{References}

[1] Alstyne, T.E.M., Platform Envelopment. Strategic Management Journal, 2011. 32: p. 1270-1285.

[2] Baldwin, C.Y. and K.B. Clark, Design Rules Volume I: The Power of Modularity. 2000. 1(1).

[3] Cusumano, M.A., The platform leader's dilemma. Communications of the Acm, 2011. 54(10): p. 21-24.

[4] Eisenmann, T.R., G. Parker and M.W. Van Alstyne, Strategies for Two Sided Markets. Social Science Electronic Publishing, 2006. 84(10): p. págs. 92-101.

[5] Gawer, A. and M.A. Cusumano, How companies become platform leaders. Mit Sloan Management Review, 2008. 49(2): p. 28-35. 
[6] Giessmann, A., et al., Towards a Better Understanding of the Dynamics of Platform as a Service Business Models. 2014.

[7] Iansiti, M. and G.L. Richards, Information Technology Ecosystem: Structure, Health, and Performance, The. Antitrust Bulletin, 2006(1).

[8] Lin, M. and X.A. Pan, Dynamic Platform Pricing with Innovative Products. Social Science Electronic Publishing, 2013.

[9] Lyons, K., et al., Business Models in Emerging Online Services. Lecture Notes in Business Information Processing, 2009. 36: p. 44-55.

[10] Robertson, D. and K. Ulrich, Planning for product platforms. Mit Sloan Management Review, 1998. 39(4): p. 19-31.

[11] Schmalensee, R. and D.S. Evans, The Industrial Organization of Markets with Two-Sided Platforms. Ssrn Electronic Journal, 2005. 3(1): p. 103-114. 